\title{
Biostimulant Activity of Trichoderma saturnisporum in Melon (Cucumis melo)
}

\author{
Diánez Fernando, Santos Milagrosa ${ }^{1}$, Carretero Francisco, \\ and Marín Francisco \\ Agronomy Department, University of Almería, La Cañada de San Urbano, \\ Almería 04120, Spain
}

Additional index words. crops, Cucumis melo Trichoderma, growth promotion, yield enhancement, fruit quality

\begin{abstract}
Trichoderma-based biostimulants are considered the most effective plant growth-promoting fungi. The purpose of this study is to determine the effect of two Trichoderma saturnisporum isolates on the growth promotion of melon (Cucumis melo) seeds and seedlings as well as their effect on the performance of the cantaloupe "Charentais" melon crop cultivar Gandalf cultivated under a typical parral-type greenhouse. For these purposes, germination trials and two experiments were performed in a commercial nursery, conventional system, and large plant system. Two experiments were also established for 2 years (two crop cycles) in a commercial greenhouse in Almería, Spain. In addition, we evaluated the influence of these isolates (T1 and T2) on the Charentais melon yield and quality. High values for seedling vigor and root length were obtained by $T$. saturnisporum $\mathrm{T} 1(93.50 \%)$ and $\mathrm{T} 2(93.75 \%)$ against control $(62 \%)$. Trichoderma saturnisporum T1 and T2 increased the quality of plants in conventional system and large plant system and can be considered as biostimulant. Trichoderma saturnisporum treatments resulted in significantly larger crop productivity without a negative effect on the fruit quality parameters. Melon productivity increased in $T$. saturnisporum treatments $\mathrm{T} 1(13.99 \%)$ and $\mathrm{T} 2(16.04 \%)$, while at the same time increases the average fruit weight up to $7.71 \%$ for $\mathrm{T} 2$ isolate. Trichoderma saturnisporum act as biostimulants for nursing and commercial melon crops without negative effects on fruit quality. This is the first report describing $T$. saturnisporum as a potential crop yield promoter.
\end{abstract}

Trichoderma is one of the most studied genera and includes plant growth-promoting fungi and biological control agents that are used against phytopathogenic fungi. Commercial formulations of Trichoderma have been developed worldwide because of their high efficacy, although most are limited to a few species, including Trichoderma harzianum, Trichoderma Asperellum, and Trichoderma viride.

Some species of Trichoderma are biostimulants, whereas others function as a control agent against fungal diseases. Plant root colonization by Trichoderma often leads to an increase in morphological parameters and crop productivity. Many studies report the benefits provided by Trichoderma to different horticultural crops, such as cucumber, pepper, chrysanthemum, and lettuce. These studies measured crop vigor, vegetative development, and flowering (López-Bucio et al., 2015).

The benefits of Trichoderma application on crop yield has also been shown with the application of $T$. harzianum to tomato (Bal and Altintas, 2006a), pepper (Bal and Altintas, 2006b), cucumber (Altintas and Bal, 2005),

Received for publication 27 Feb. 2018. Accepted for publication 2 Apr. 2018.

Francisco Carretero was the recipient of a fellowship from the Spanish Ministry of Science and Innovation.

${ }^{1}$ Corresponding author. E-mail: msantos@ual.es. and energy crops (Chirino-Valle et al., 2016). In experiments performed in greenhouses, there was a considerable yield increase when plant seeds were previously treated with spores from Trichoderma (Chet, 1987). These benefits are associated with the reduction of salinity stress and a lower incidence of diseases (Harman et al., 2004). Elad et al. (1986) reported that in a commercial field experiment, testing the ability of four T. harzianum isolates to control charcoal rot (Macrophomina phaseolina) of melons, Trichoderma treatments increased the total yield by $5.8 \%$ to $8.9 \%$ compared with the untreated control.

Recently, Diánez et al. (2016) characterized $T$. saturnisporum as a new biological control agent against Phytophthora parasitica and Phytophthora capsici and showed improved development of pepper seedlings. Several mechanisms that may support its potential as a growth promoter and biocontrol agent have been described for T. saturnisporum and include the production of siderophores, indole acetic acid (IAA), and other metabolites.

The incorporation of Trichoderma in agricultural production systems may reduce the current dependence on fertilizers and phytosanitary products for the control of diseases. These goals are increasingly valued by consumers and agri-food supply chains.

In the present study, two T. saturnisporum isolates were tested to evaluate their capacity as biostimulants to enhance seed germination and melon vigor; promote the growth and quality of melon seedlings under a conventional production system ( $35 \mathrm{~d}$ ) and in a system called "big plant"; and their effect on the yield and fruit quality parameters of a Cantaloupe(Charentais) type melon crop (Cucumis melo L. cv. Gandalf) under greenhouse.

\section{Materials and Methods}

Isolates of $T$. saturnisporum used in experiments

Two isolates of T. saturnisporum (T1 and T2) were selected for their known antagonistic activity and plant growth promotion in pepper (Diánez et al., 2016).

Each isolate was grown on potato dextrose agar (PDA, Bioxon, Mexico City, Mexico) for $15 \mathrm{~d}$ at $25-27 \pm 2{ }^{\circ} \mathrm{C}$ under dark conditions. Spore suspensions were prepared in sterile distilled water and adjusted to a concentration of $1 \times 10^{9}$ spores $/ \mathrm{mL}$ with a Neubauer hemocytometer.

Experiment 1: Evaluation of $T$. saturnisporum isolates to enhance germination and root vigor on melon seeds

Seeds of melon C. melo L. cv. Gandalf were used in this study. Two isolates of $T$. saturnisporum were inoculated over melon seeds, and germination and early seedling growth were studied. The trial used a random block experimental design with three treatments (Control, T1, and T2) and four repetitions. Each repetition included 50 seeds that were germinated in petri dishes $(150 \mathrm{~mm}$ of diameter) containing two sheets of Whatman No. 1 filter paper that were moistened with sterile distilled water. The melon seeds were surface sterilized with $1.5 \%$ sodium hypochlorite $(\mathrm{NaOCl})$ for $5 \mathrm{~min}$ and rinsed twice with sterile distilled water and dried under laminar air flow on sterile paper (Jain et al., 2013). Treatments were performed by pipetting $30 \mu \mathrm{L}$ of a Trichoderma (T1 or T2) spore suspension $\left(1 \times 10^{8}\right.$ spores $\left./ \mathrm{mL}\right)$ or $30 \mu \mathrm{L}$ of water (control) on each seed; all boxes were placed in an incubator $\left(25 \pm 1{ }^{\circ} \mathrm{C}\right.$ in dark).

The number of germinated seeds was counted daily for up $7 \mathrm{~d}$. Seed vigor index (Abul-Baki and Anderson, 1973) was calculated based on the percentage of germination $(\%)$ and seedling length $(\mathrm{cm})$. Root length $(\mathrm{mm})$ was measured from the tip of the primary root to the base of the hypocotyl.

Experiment 2 and 3: Promoter effects of T. saturnisporum isolates on melon seedlings

Two experiments were performed in a commercial nursery (Almería, Spain). Experiment 2 was designed to evaluate the effect of T. saturnisporum isolates to enhance the seedling quality of melon under a conventional production system ( $35 \mathrm{~d})$. Experiment 3 was designed to evaluate the effect of $T$. saturnisporum isolates to enhance melon seedling quality under a system called "big plant." The "big plant" system enables nurseries to produce larger plants than conventional systems $(35+20 \mathrm{~d})$. 
Experiment 2. This experiment was performed in nursery polystyrene planting trays, each with 96 cells ( $70 \mathrm{~mL}$ volume). Melon seedlings cv. Gandalf were grown for $35 \mathrm{~d}$ in commercial nursery as described by Diánez et al. (2016).

Spore suspension $\left(1.5 \times 10^{5}\right.$ spores/plant of T1 and T2) was applied by mixing (M) substrate (sowing day) or irrigating (I) (2 d after sowing).

The trials used a random block experimental design with five treatments and four repetitions according to the following linear additive statistical model: $\gamma_{i j}=\mu+\alpha_{i}+\beta_{j}+$ $\varepsilon_{i j}$ where $i=1,2,3,4,5$; and $j=1,2,3,4$.

Experiment 3. The experiment was performed during 20 additional days $(35+20 \mathrm{~d})$ in a system called "big plant" in PE containers (200 mL volume). Four specific trays were used for each treatment, with 10 replications per tray. These were previously selected from treatment " $\mathrm{M}$ " from Experiment 2, transplanted to the same substrate mixed with $2.4 \times 10^{3}$ spores $/ \mathrm{mL}\left(4.8 \times 10^{5}\right.$ spores/plant), and compared with controls. For evaluation, 10 seedlings were selected at random in each tray for each repetition, treatment, and experiment.

For both experiments, different morphological parameters were determined, including the number of leaves, stem length, stem base diameter, total leaf area, and stem, leaf and root dry weights. Leaf area was measured using the WINDIAS 3.1 (Delta-T Devices, Ltd., Cambridge, UK, 2009) leaf area processing program. Four different seedling quality indices were also calculated: Slenderness index (SR) (stem height/stem diameter, Ritchie, 1984), Dickson quality index (DQI) (Dickson et al., 1960), leaf area ratio index (LAR) (total leaf area/plant dry weight. proposed by Briggs et al. (1920), and specific leaf area (SLA) (leaf area/leaf weight; Herrera et al., 2008, 2009). The experiments were conducted using completely randomized designs. In the "big plant" assay, secondary stem plant height and secondary stem plant weight were also determined. Descriptive statistics were performed for all measured parameters. Data were analyzed by analyses of variance (ANOVA), and treatment means were compared using the least significant difference test at $P \leq 0.05$.

Experiment 4: Evaluation of effect of $\boldsymbol{T}$. saturnisporum isolates to enhance yield of Cantaloupe- (Charentais) type melon crop in a typical parral-type greenhouse

Fields experiments were performed in Níjar (Almería), southeast Spain under a typical parral-type greenhouse during the productive seasons.

A greenhouse $\left(8500 \mathrm{~m}^{2}\right)$ was used, with a trithermal polyethylene lining of 800 gauge and zenith and side screens with 50-mesh density. Climate control was passive. In May and June, the plastic cover was limed with calcium carbonate as a control of high temperatures. Cultures were grown on modified soil, locally known as "suelo arenado." The plant material used was the melon (C. melo L. cv. Gandalf).
In both assays, the melon growing cycle was $\approx 3$ months; plants were transplanted in mid-February and the last harvest was made in mid-May.

In transplants, microelements, amino acids (Rizosane $^{\circledR}$, S.L. NUTRICROP, Almería, Spain), $\left(1 \mathrm{~cm}^{3} \cdot \mathrm{L}^{-1}\right)$, and humic acid $\left(10 \mathrm{~cm}^{3} \cdot \mathrm{L}^{-1}\right)$ were applied via irrigation. Water requirements were established according to climatic conditions and crop needs. Fertigation was performed three times per week. The trials used a random block experimental design with four treatments and four repetitions, according to the following linear additive statistical model $\gamma_{i j}=\mu+\alpha_{i}+\beta_{j}+\varepsilon_{i j}$, where $i=1,2,3,4$; and $j=1,2,3,4$ for both studies.

The greenhouses were divided into four blocks; random treatments were applied in each block, for a total of the aforementioned four repetitions. The number of plants per elemental block was 50 , at a density of 0.71 plants $/ \mathrm{m}^{2}$.

Two isolates of $T$. saturnisporum ( $\mathrm{T} 1$ and $\mathrm{T} 2$ ) and a commercial $T$. asperellum $(\mathrm{Tc})$ were used. Plants were manually irrigated with $300 \mathrm{~mL}$ of spores suspension per plant at $4.2 \times 10^{7}$ spores/plant. In the control (T0), only water was applied. This operation was made at $0 \mathrm{~d}$ (days after transplanting) and repeated at $21 \mathrm{~d}$ in both years.

Harvesting was performed daily, and yield was measured in both experiments. Fruit were harvested during the third and fourth week of May in both years.

A sample of 25 fruit was taken at random per harvest and elemental plot. Polar perimeter (PP), equatorial perimeter (EP), and weight were measured. A flexometer with a sensitivity of $1 \mathrm{~mm}$ was used for measuring PP and EP. An AJH-3200 precision balance with a sensitivity of $0.01 \mathrm{~g}$ was used for weight determination.

The total number of fruit per harvest and elemental plot was counted; fruit yield per plot was calculated as the average weight of 25 harvested fruit per plot, as well as the number of fruit counted per plot and harvest. The number of fruit per surface unit $\left(\mathrm{m}^{2}\right)$ and plot was calculated. Average fruit weight (AFW) and average PP/EP relationship were determined for 25 fruit from each plot at each harvest.

Five fruit on alternate harvesting days were selected at random from each repetition (20 fruit per treatment) for quality measurements. Three different measurements were taken per fruit. The parameters evaluated were pulp firmness, total soluble solid ( ${ }^{\circ}$ Brix), $\mathrm{pH}$, size of pistil scar, and rind thickness. The firmness of the pulp is the mean value of three different points measured below the equatorial axis of the fruit and was determined using a penetrometer with a probe of $0.5 \mathrm{~cm}^{2}$ and a scale of 0 to 30 $\mathrm{kg}$. This measurement indicates the consistency of the pulp. Total soluble solids (TSS) content was measured with a refractometer with a scale from $0 \%$ to $32 \%$ and a sensitivity of $0.2 \%$. The $\mathrm{pH}$ was measured with a $\mathrm{pH}$ meter with a precision of \pm 0.01 units. A caliper with a sensitivity of $0.01 \mathrm{~mm}$ was used for measuring rind width and the size of the pistil.

\section{Statistical analysis}

All data were analyzed using Fisher's least significant difference procedure $(P \leq$ 0.05). A combined ANOVA without interaction for a complete set of combined experiments as split plots was performed as recommend by Fernández-Escobar et al. (2010). The logarithm and square root transformations were used if the ANOVA assumptions of homogeneity or normality were violated. The mean and $90 \%$ confidence intervals were calculated if possible. Statgraphics Centurion XV was used.

\section{Results}

Experiment 1: Evaluation of $\boldsymbol{T}$. saturnisporum isolates to enhance germination and root vigor on melon seeds

The effects of two Trichoderma isolates on the seed germination parameters of melon are presented in Table 1. Direct inoculation of seeds by $T$. saturnisporum isolate spores had a significant effect $(P \leq 0.01)$ on percentage seed germination, root length, and seed vigor index. Both isolates gave similar values in terms of germination percentage $(93.50 \%$ and $93.75 \%$ ). The highest values for seedling vigor and root length were obtained by $\mathrm{T} 2$.

\section{Promoter effects of $\boldsymbol{T}$. saturnisporum isolates on melon seedlings}

Experiment 2. The effect of Trichoderma application by irrigation or substrate mixing on morphological parameters and plant quality indices is shown in Table 2. Trichoderma applications resulted in increases in most of the growth parameters evaluated. Higher values were observed for stem base diameter, stem length, stem dry weight, total dry weight, leaf dry weight, and leaf area compared with the experimental control. These increases were statistically significant in some cases. The greatest increases were $29 \%$ for stem length ( $\operatorname{Tr} 2), 19.85 \%$, and $23.5 \%$ for dry stems for $\operatorname{Tr} 1$ and $\operatorname{Tr} 2$, respectively, and $13.8 \%$ for leaf area $(\operatorname{Tr} 1)$, in comparison with the experimental control. Irrigation gave the largest increases in plant parameters, because this method increased several evaluated parameters; these increases were statistically significant in most cases. However, Trichoderma applications resulted in a decrease in root dry weight. Analysis of quality indices, indicate that Trichoderma application in substrate gave plants whose index values were positively altered compared with control plants for the two quality indices. Large values are desirable for DQI and SR indices, whereas small values are best for SLA and LAR indices. For LAR and SLA, Tm1 and Tm2 gave significantly improved values over the control.

Experiment 3. The effect of the promoter of T. saturnisporum on melon seedlings under the "big plant" production system is shown in Table 3 . After $55 \mathrm{~d}$ of cultivation, 
$\mathrm{T} 1$ and $\mathrm{T} 2$ were highly effective in promoting the growth of melon seedling plants. The largest significant increases were $24.60 \%$ (T1) and $28.81 \%$ (T2) for stem length; $5.74 \%$ (T1) and $4.67 \%$ (T2) for diameter; $8.5 \%$ (T1) and $11.46 \%$ (T2) for leaf dry weight; $17.28 \%$ (T1) and $22.22 \%$ (T2) for principal stem dry weight; $34.48 \%$ (T1) and $37.93 \%$ (T2) for root dry weight; $15.15 \%$ (T1 and T2) for total dry weight; and $11.60 \%$ (T1) and $13.55 \%$ (T2) for leaf area, compared with control plants.

For root and stem indices, SLA and DQI, $\mathrm{T} 1$ and T2 gave significantly improved indices compared with control results. No significant difference among treatments was observed for both isolates, although T2 obtained better results.

Experiment 4: Evaluation of the ability of $T$. saturnisporum to enhance yield of a Cantaloupe- (Charentais) type melon crop under a typical parral-type greenhouse: Productive parameters

Field evaluations were undertaken using different climate and soil conditions in the 2-year trials. Harvesting began $85 \mathrm{~d}$ after transplanting in Experiment 1 and $75 \mathrm{~d}$ after transplanting in Experiment 2. Table 4 shows the influence of different Trichoderma treatments on total yield $\left(\mathrm{kg} \cdot \mathrm{m}^{-2}\right)$ and profit components (AFW and fruit/plant) for 'Gandalf' melon in both years.

Both isolates of $T$. saturnisporum increased melon productivity in both years. In year 1 , the increase was $4.10 \%, 19.84 \%$, and $3.79 \%$ in $\mathrm{T} 1, \mathrm{~T} 2$, and $\mathrm{Tc}$, respectively, compared with controls (T0). T2 and T0 showed statistically significant differences. In year 2 , total yield increased by $24.81 \%$, $10.74 \%$, and $2.22 \%$ in $\mathrm{T} 1, \mathrm{~T} 2$, and $\mathrm{Tc}$, respectively, compared with controls. Statistically significant differences were observed between T. saturnisporum treatments ( $\mathrm{T} 1$ and T2) compared with the control. A combined ANOVA without interaction for a complete set of combined experiments were performed as Split Plots. Statistically, higher melon production was noted from plants treated with T1 (13.99\%) and T2 (16.04\%) compared with control plots. The results are shown in Table 4.

Table 1. Effect of T. saturnisporum isolates (T1, T2, $30 \mu \mathrm{L}$ of a suspension of $1 \times 10^{8}$ spores $/ \mathrm{mL}$ ) on melon seed germination $7 \mathrm{~d}$ after treatment.

\begin{tabular}{lccc}
\hline & \% Germination & Root length $(\mathrm{mm})$ & Seed vigor index \\
\hline$P$ value & $P=0.0013$ & $P=0.0000$ & $P=0.0143$ \\
T1 & $93.50 \pm 9.14 \mathrm{~b}^{\mathrm{z}}$ & $47.20 \pm 15.77 \mathrm{a}$ & $4,487.75 \pm 176.95 \mathrm{~b}$ \\
T2 & $93.75 \pm 12.5 \mathrm{~b}$ & $55.56 \pm 19.21 \mathrm{~b}$ & $5,295.0 \pm 1,430.89 \mathrm{~b}$ \\
T0 & $62 \pm 4.69 \mathrm{a}$ & $47.28 \pm 17.90 \mathrm{a}$ & $2,958.61 \pm 559.18 \mathrm{a}$ \\
\hline
\end{tabular}

${ }^{\mathrm{z}}$ Different letters indicate significant differences according to analyses of variance $(P<0.05)$.

$\mathrm{T} 2$ increased $\mathrm{AFW}$ in both the first $(3.86 \%)$ and second year $(7.71 \%)$, with a statistically significant difference from the control. In T1, a significant increase $(4.96 \%)$ was observed only in the second experiment. A small decrease was observed in plants treated with Tc compared with the control in both experiments $(-0.21 \%$ and $-1.45 \%$ on experiments 1 and 2 , respectively) but without statistically significant differences in the controls. Regarding the number of fruit per plant, T2 increased this parameter in both the first $(10.23 \%)$ and second year $(10.30 \%)$, with statistically significant differences from the control. Nevertheless, T1 and Tc significantly increased the number of fruit only in the second year $(17.98 \%$ and $9.70 \%)$ compared with the control. A combined ANOVA without interaction indicated that significant differences were noted compared with the control. Both isolates (T1 and T2) of $T$. saturnisporum increased by $10.36 \%$ melon fruit per plant compared with controls. Trichoderma asperellum (Tc) increased the number of fruit per plant $(3.77 \%)$, without significant differences from the control.

\section{Quality parameters}

The results obtained from the fruit quality parameters are shown in Table 5. On average, soluble solids ( ${ }^{\circ}$ Brix) content in $\mathrm{T} 1$ was higher than in other treatments but there was no significant difference between them. The average soluble solid content values of fruit at harvest were for all treatments between $9.55-10.07$ and $9.75-10.16^{\circ}$ Brix in

Table 2. Morphological parameters and quality index of melon plants treated with T. saturnisporum isolates. T1 and T2 applied by irrigating (Tr1 and Tr2) or by mixing with the substrate ( $\mathrm{Tm} 1$ and $\mathrm{Tm} 2$ ) comparing with control (T0).

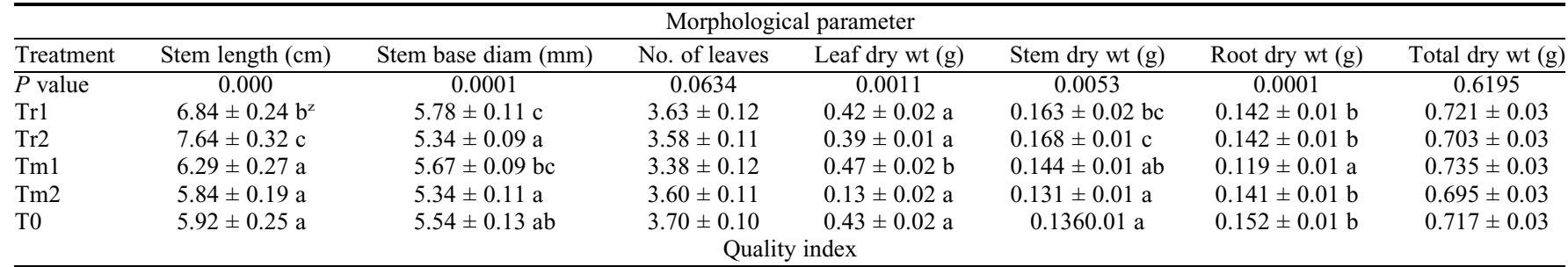

\begin{tabular}{|c|c|c|c|c|c|c|}
\hline Treatment & Leaf área $\left(\mathrm{cm}^{2}\right)$ & Slenderness index & Root and shoot index & Specific leaf area & Leaf area ratio & Dickson quality index \\
\hline Tr2 & $97.60 \pm 2.89 \mathrm{c}$ & $1.94 \pm 0.04 \mathrm{a}$ & $1.21 \pm 0.05 \mathrm{c}$ & $250.58 \pm 5.024 \mathrm{c}$ & $139.56 \pm 5.02 \mathrm{c}$ & $0.046 \pm 0.01 \mathrm{a}$ \\
\hline Tm1 & $87.56 \pm 2.70 \mathrm{ab}$ & $2.15 \pm 0.04 \mathrm{c}$ & $1.28 \pm 0.08 \mathrm{c}$ & $187.34 \pm 3.77 \mathrm{a}$ & $120.22 \pm 2.39 \mathrm{a}$ & $0.061 \pm 0.01 \mathrm{bc}$ \\
\hline T0 & $92.05 \pm 4.41 \mathrm{bc}$ & $2.14 \pm 0.05 \mathrm{bc}$ & $0.95 \pm 0.09 \mathrm{a}$ & $218.05 \pm 6.78 \mathrm{~b}$ & $129.03 \pm 6.78 \mathrm{~b}$ & $0.063 \pm 0.01 \mathrm{c}$ \\
\hline
\end{tabular}

${ }^{\mathrm{z}}$ Different letters indicate significant differences according to analyses of variance $(P<0.05)$.

Table 3. Effect of T. saturnisporum strains (T1 and T2) $\left(2.5 \times 10^{5}\right.$ spores/plant) to enhance seedling quality of melon under big plant production system.

\begin{tabular}{|c|c|c|c|c|c|c|c|c|c|c|}
\hline Treatment & \multicolumn{2}{|c|}{ Length of stem $(\mathrm{cm})$} & \multicolumn{2}{|c|}{$\operatorname{Diam}(\mathrm{mm})$} & \multicolumn{2}{|c|}{ Number of leaves } & \multicolumn{2}{|c|}{ Leaf dry wt (g) } & Stem dry wt (g) & Root dry wt (g) \\
\hline$P$ value & \multicolumn{2}{|c|}{0.0001} & \multicolumn{2}{|c|}{0.0044} & \multicolumn{2}{|c|}{0.0538} & \multicolumn{2}{|c|}{0.0599} & 0 & 0 \\
\hline $\mathrm{T} 1$ & \multicolumn{2}{|c|}{$33.17 \pm 1.23 b$} & & $3 \pm 0.10 b$ & & $22 \pm 0.49 \mathrm{~b}$ & 1.922 & $\pm 0.05 \mathrm{~b}$ & $0.95 \pm 0.03 b$ & $0.39 \pm 0.02 b$ \\
\hline $\mathrm{T} 2$ & \multicolumn{2}{|c|}{$34.29 \pm 1.29 b$} & & $4 \pm 0.07 b$ & & $31 \pm 0.46 \mathrm{ab}$ & 1.973 & $\pm 0.05 \mathrm{~b}$ & $0.99 \pm 0.02 b$ & $0.40 \pm 0.01 \mathrm{~b}$ \\
\hline Control & \multicolumn{2}{|c|}{$26.62 \pm 1.23 \mathrm{a}$} & & $5 \pm 0.13 \mathrm{a}$ & & $78 \pm 0.42 \mathrm{a}$ & 1.77 & $\pm 0.05 \mathrm{a}$ & $0.81 \pm 0.03 \mathrm{a}$ & $0.29 \pm 0.01 \mathrm{a}$ \\
\hline Treatment & Total dry wt (g) & Leaf are & & Root and $\mathrm{s}$ & dex & Specific leaf a & $\left.\mathrm{m}^{2} \cdot \mathrm{g}^{-1}\right)$ & Leaf are & ficient $\left(\mathrm{cm}^{2} \cdot \mathrm{g}^{-1}\right)$ & Dickson quality index \\
\hline$P$ value & 0.0004 & 0.00 & & 0.01 & & 0.66 & & & 625 & 0.0349 \\
\hline $\mathrm{T} 1$ & $3.42 \pm 0.09 \mathrm{~b}^{\mathrm{z}}$ & $507.86 \pm$ & & $2.49 \pm$ & & $265.67 \pm$ & & & $\pm 3.12 \mathrm{a}$ & $0.56 \pm 0.02 \mathrm{~b}$ \\
\hline $\mathrm{T} 2$ & $3.42 \pm 0.09 \mathrm{~b}$ & $516.74 \pm$ & & $2.53 \pm$ & & $258.42 \pm$ & & & $\pm 2.98 \mathrm{a}$ & $0.54 \pm 0.02 \mathrm{ab}$ \\
\hline Control & $2.97 \pm 0.09 \mathrm{a}$ & $455.07 \pm$ & & $2.92 \pm$ & & $258.72 \pm$ & & & $\pm 3.73 \mathrm{a}$ & $0.49 \pm 0.02 \mathrm{a}$ \\
\hline
\end{tabular}

${ }^{\mathrm{z}}$ Different letters indicate significant differences according to analyses of variance $(P<0.05)$. 
the first and second experiments, and 9.66$10.11^{\circ}$ Brix in a combined analysis. The average $\mathrm{pH}$ values of fruit at harvest were for all treatments between 6.26-6.32 and 6.33-6.40 in the first and second experiments, and 6.30-6.36 in a combined analysis. There were no statistically significant differences in average $\mathrm{pH}$. Pulp firmness did not show significant differences between treatments. Pulp firmness values varied from 1.77 to $1.84 \mathrm{~kg} \cdot \mathrm{cm}^{-2}$ and 1.70 to $1.86 \mathrm{~kg} \cdot \mathrm{cm}^{-2}$ for the first and second experiments, respectively. The combined average values in both experiments varied from 1.70 to $1.84 \mathrm{~kg} \cdot \mathrm{cm}^{-2}$. There were no statistically significant differences in average pulp firmness value. The size of the pistil scars showed no statistically significant differences between treatments. Measured averages were 15.35, 15.45, and and combined values, respectively. Average rind thickness measurements oscillated between 3.00-3.24, 3.02-3.28, and 3.01$3.16 \mathrm{~mm}$ for Experiment 1, Experiment 2, $15.40 \mathrm{~mm}$ for Experiment 1, Experiment 2,

and both experiments, respectively; there were no statistically significant differences between treatments. The results from PP showed no statistically significant differences between treatments for each season. Nevertheless, when a combined ANOVA without interaction was performed, statistically significant differences between treatments were found. The highest fruit perimeters were in $\mathrm{T} 2(38.03 \mathrm{~cm})$ and T1 $(37.66 \mathrm{~cm})$. The results from EP were higher in T2; in all comparisons there was a statistical difference from the control. When a combined ANOVA without interaction was performed, there were differences between $\mathrm{T} 1(36.13 \mathrm{~cm})$ and $\mathrm{T} 2$ $(36.63 \mathrm{~cm})$ for $\mathrm{Tc}(35.84 \mathrm{~cm})$ and control $(35.87 \mathrm{~cm})$. The values of the PP/EP ratio did not show statistically significant differences.

\section{Discussion}

Many studies report the biostimulant and/ or biofertilizer activity of different Trichoderma species, both in vitro and in vivo. For

Table 4. Effect of T. saturnisporum isolates (T1 and T2) and commercial Trichoderma (Tc) on production and on main yield components in Gandalf $\mathrm{cv}$.

\begin{tabular}{lccc}
\hline Treatment & $\mathrm{kg} \cdot \mathrm{m}^{-2}$ & Avg fruit $\mathrm{wt}(\mathrm{g})$ & Fruit/plant \\
\hline & & First year & \\
$P$ value & $P=0.0412$ & $P=0.0004$ & $P=0.0114$ \\
T1 & $3.30 \pm 0.16 \mathrm{a}^{\mathbf{z}}$ & $800.12 \pm 8.83 \mathrm{a}$ & $5.87 \pm 0.30 \mathrm{a}$ \\
$\mathrm{T} 2$ & $3.80 \pm 0.19 \mathrm{~b}$ & $847.81 \pm 13.21 \mathrm{~b}$ & $6.25 \pm 0.33 \mathrm{~b}$ \\
Tc & $3.29 \pm 0.21 \mathrm{a}$ & $814.60 \pm 40.68 \mathrm{a}$ & $5.59 \pm 0.31 \mathrm{a}$ \\
T0 & $3.17 \pm 0.13 \mathrm{a}$ & $816.29 \pm 23.01 \mathrm{a}$ & $5.67 \pm 0.29 \mathrm{a}$ \\
& & Second year & \\
$P$ value & $P=0.0462$ & $P \approx 0.0000$ & $P=0.0066$ \\
T1 & $3.37 \pm 0.17 \mathrm{c}$ & $778.02 \pm 17.31 \mathrm{~b}$ & $5.84 \pm 0.26 \mathrm{~b}$ \\
T2 & $2.99 \pm 0.25 \mathrm{~b}$ & $730.41 \pm 25.10 \mathrm{~b}$ & $5.46 \pm 0.41 \mathrm{~b}$ \\
Tc & $2.76 \pm 0.30 \mathrm{ab}$ & $741.28 \pm 15.47 \mathrm{a}$ & $5.43 \pm 0.40 \mathrm{~b}$ \\
T0 & $2.70 \pm 0.18 \mathrm{a}$ & & $4.95 \pm 0.25 \mathrm{a}$ \\
& & Combined analysis & \\
$P$ value & $P=0.0471$ & $P=0.0067$ & $P=0.0006$ \\
T1 & $3.34 \pm 0.16 \mathrm{~b}$ & $776.09 \pm 12.28 \mathrm{~b}$ & $5.86 \pm 0.24 \mathrm{~b}$ \\
T2 & $3.40 \pm 0.21 \mathrm{~b}$ & $809.36 \pm 9.17 \mathrm{~b}$ & $5.86 \pm 0.27 \mathrm{~b}$ \\
Tc & $3.03 \pm 0.16 \mathrm{a}$ & $755.50 \pm 34.01 \mathrm{a}$ & $5.51 \pm 0.24 \mathrm{a}$ \\
T0 & $2.93 \pm 0.14 \mathrm{a}$ & $759.81 \pm 11.73 \mathrm{a}$ & $5.31 \pm 0.25 \mathrm{a}$ \\
\hline
\end{tabular}

${ }^{\mathrm{z}}$ Numbers followed by different letters denote statistical significance according to Fisher's least significant difference test $(P<0.05)$. example, Pereira et al. (2014) described an increase in the size of bean seedlings after the application of $T$. harzianum under in vitro conditions. Similarly, the application of $T$. harzianum increased plant growth and biomass of melon stems in commercial seedling nurseries (Martínez-Medina et al., 2009). Under field and greenhouse conditions, some reports have shown increases in the chlorophyll content and dry weight of zucchini roots using Trichoderma atroviride (Colla et al., 2015); growth promotion in tomato plants after the application of Trichoderma parareesei (Rubio et al., 2012); promotion of seed germination; and increases in dry root weight of peppers using $T$. harzianum (Chang et al., 1986) and T. atroviride (Colla et al., 2015).

In this study, $T$. saturnisporum isolates enhance germination and root vigor in melon seeds and enhance several parameters in seedling plants produced on "conventional" and "big plant" systems. The results have shown that $T$. saturnisporum application via irrigation in conventional systems significantly increased stem diameter, stem length, stem dry weight, and leaf area. In addition, results have shown that $T$. saturnisporum application via irrigation in a "big plant" system significantly increased all parameters studied. Diánez et al. (2016) described for the first time a biostimulant effect of $T$. saturnisporum on pepper seedlings that were kept for $50 \mathrm{~d}$ in commercial seedbeds; they noted a $17 \%$ increase in total seedling dry weight. This increase was similar to that $(15.15 \%)$ found in melon seedlings that were grown for $55 \mathrm{~d}$. There was no influence on melon plants grown for only $30 \mathrm{~d}$ in the conventional system. Similar results were obtained by Marín-Guirao et al. (2016) after 30 d of inoculation of T. saturnisporum $\mathrm{T} 1$ in pepper, tomato, and cucumber seedlings. These results suggest that the application of $T$. saturnisporum requires more than $30 \mathrm{~d}$ (the standard residence time of seedlings in the nursery) to promote plant growth. However,

Table 5. Effect of Trichoderma isolates on quality parameters in Gandalf cv. Melon.

\begin{tabular}{lcccccccc}
\hline Treatment & ${ }^{\circ}$ Brix & $\mathrm{pH}$ & $\begin{array}{c}\text { Pulp firmness } \\
\left(\mathrm{kg} \cdot \mathrm{cm}^{-2}\right)\end{array}$ & $\begin{array}{c}\text { Rind thickness }(\mathrm{mm}) \\
\text { Pristil scar }(\mathrm{mm})\end{array}$ & $\begin{array}{c}\text { Polar perimeter }(\mathrm{cm}) \\
\text { perimeter }(\mathrm{cm})\end{array}$ & $\begin{array}{c}\text { Fquatorial } \\
\text { PP/EP }\end{array}$ \\
\hline$P$ value & $P=0.1170$ & $P=0.6631$ & $P=0.4807$ & $P=0.5329$ & $P=0.1010$ & $P=0.3729$ & $P=0.0003$ & $P=0.1857$ \\
T1 & $10.07 \pm 0.06$ & $6.33 \pm 0.01$ & $1.84 \pm 0.04$ & $3.24 \pm 0.03$ & $15.71 \pm 0.15$ & $37.83 \pm 0.11$ & $36.17 \pm 0.11 \mathrm{a}^{\mathrm{z}}$ & $1.046 \pm 0.001$ \\
T2 & $9.70 \pm 0.05$ & $6.31 \pm 0.01$ & $1.81 \pm 0.03$ & $3.20 \pm 0.03$ & $15.78 \pm 0.15$ & $38.40 \pm 0.11$ & $36.89 \pm 0.10 \mathrm{~b}$ & $1.042 \pm 0.001$ \\
Tc & $9.55 \pm 0.04$ & $6.26 \pm 0.01$ & $1.68 \pm 0.03$ & $3.02 \pm 0.02$ & $14.87 \pm 0.15$ & $37.99 \pm 0.12$ & $36.35 \pm 0.11 \mathrm{a}$ & $1.045 \pm 0.001$ \\
T0 & $9.83 \pm 0.06$ & $6.32 \pm 0.01$ & $1.77 \pm 0.03$ & $3.00 \pm 0.03$ & $15.27 \pm 0.19$ & $37.92 \pm 0.11$ & $36.35 \pm 0.11 \mathrm{a}$ & $1.044 \pm 0.001$ \\
& & & & Second year & & & \\
$P$ value & $P=0.2110$ & $P=0.5161$ & $P=0.4902$ & $P=0.0733$ & $P=0.2112$ & $P=0.2458$ & $P \approx 0.0000$ & $P=0.1645$ \\
T1 & $10.16 \pm 0.04$ & $6.40 \pm 0.01$ & $1.86 \pm 0.04$ & $3.28 \pm 0.13$ & $15.87 \pm 0.16$ & $36.53 \pm 0.13$ & $36.36 \pm 0.12 \mathrm{~b}$ & $1.039 \pm 0.001$ \\
T2 & $9.80 \pm 0.03$ & $6.36 \pm 0.01$ & $1.83 \pm 0.03$ & $3.15 \pm 0.14$ & $15.82 \pm 0.14$ & $36.67 \pm 0.12$ & $36.36 \pm 0.12 \mathrm{~b}$ & $1.036 \pm 0.001$ \\
Tc & $9.75 \pm 0.03$ & $6.33 \pm 0.01$ & $1.70 \pm 0.03$ & $3.04 \pm 0.15$ & $14.85 \pm 0.16$ & $37.43 \pm 0.13$ & $35.36 \pm 0.12 \mathrm{a}$ & $1.036 \pm 0.001$ \\
T0 & $9.93 \pm 0.03$ & $6.39 \pm 0.01$ & $1.79 \pm 0.03$ & $3.02 \pm 0.12$ & $15.43 \pm 0.19$ & $37.64 \pm 0.13$ & $35.41 \pm 0.13 \mathrm{a}$ & $1.040 \pm 0.001$ \\
& & & & & & & & \\
$P$ value & $P=0.1811$ & $P=0.1927$ & $P=0.1745$ & $P=0.1697$ & $P=0.1352$ & $P=0.0003$ & $P \approx 0.0000$ & $P=0.8756$ \\
T1 & $10.11 \pm 0.05$ & $6.36 \pm 0.01$ & $1.85 \pm 0.03$ & $3.26 \pm 0.08$ & $15.79 \pm 0.19$ & $37.66 \pm 0.11 \mathrm{~b}$ & $36.13 \pm 0.11 \mathrm{~b}$ & $1.043 \pm 0.001$ \\
T2 & $9.75 \pm 0.07$ & $6.34 \pm 0.44$ & $1.82 \pm 0.10$ & $3.17 \pm 0.29$ & $15.79 \pm 0.15$ & $38.03 \pm 0.11 \mathrm{c}$ & $36.63 \pm 0.10 \mathrm{c}$ & $1.039 \pm 0.001$ \\
Tc & $9.66 \pm 0.04$ & $6.30 \pm 0.01$ & $1.70 \pm 0.02$ & $3.03 \pm 0.09$ & $14.85 \pm 0.18$ & $37.24 \pm 0.12 \mathrm{a}$ & $35.84 \pm 0.11 \mathrm{a}$ & $1.039 \pm 0.001$ \\
T0 & $9.88 \pm 0.05$ & $6.35 \pm 0.07$ & $1.78 \pm 0.02$ & $3.01 \pm 0.07$ & $15.35 \pm 0.22$ & $37.28 \pm 0.13 \mathrm{a}$ & $35.87 \pm 0.12 \mathrm{a}$ & $1.039 \pm 0.001$ \\
\hline
\end{tabular}

${ }^{\mathrm{z}}$ Numbers followed by different letters denote statistical significance according to Fisher's least significant difference test $(P<0.05)$.

$\mathrm{EP}=$ equatorial perimeter; $\mathrm{PP}=$ polar perimeter. 
inoculation of T. saturnisporum in the seedling phase after transplanting increased the yield of melon crops for two growing seasons.

Different authors establish the direct relationship between the resistance of the seedlings to the transplant stress and the subsequent early and total production with the dry matter content (Basoccu and Nicola, 1989; Castillo et al., 2004; Herrera et al., 2008; Pimpini and Gianquinto, 1991). According to Herrera et al. (2008), the leaf area of the tomato seedlings seems to be directly related to the production of fruit per plant.

In our study, the incorporation of $T$. saturnisporum in melon crops produced higher yields and fruit quality compared with the control and commercial products. In addition, these results confirm those obtained by Herrera et al. (2008), because both melon isolates showed increased leaf area.

By contrast to our results, MartínezMedina et al. (2011) found that T. harzianuminoculated melon plants did not differ in fruit number relative to noninoculated plants.

Maturity indices play a very important role in the postharvest quality management of cantaloupes. The main factors limiting melon fruit quality are texture, sweetness, and odor (Luna-Guzmán et al., 1999; Portela and Cantwell, 1998; Pratt, 1971). Cantaloupes are harvested by maturity rather than size. The determination of harvest maturity is particularly difficult in honeydew melons, because the abscission zone, a useful harvest criteria for cantaloupes, does not form until the fruit are overripe (Pratt et al., 1977). The market quality of melon fruit is determined based on sugar content and, more routinely, as the TSS content measured in ${ }^{\circ}$ Brix (Lester and Dunlap, 1985; Villanueva et al., 2004). In this research, ${ }^{\circ}$ Brix values were within the acceptable commercial requirements. Soluble solids content always had higher values than the minimum (9) acceptable market values for all melons (Shellie and Lester, 2004) and especially for cantaloupes (Fonseca, 2005). The TSS content recommended for melon fruit sold in markets should be higher than or equal to $9{ }^{\circ}$ Brix for cantaloupes (NFSMI, 2013) (National Food Services Management Institute). The $\mathrm{pH}$ of the intact fruit remained at $\approx 6$, in accordance with Supapvanich et al. (2011). Portela and Cantwell (1998) observed an average pulp firmness of $1.75 \mathrm{~kg} \cdot \mathrm{cm}^{-2}$ at harvest. The results from the present study showed that all T. saturnisporum treatments were above this value. The commercial quality standards developed by UNECE (2010) (United Nations Economic Commission for Europe) reports a minimum size, by weight, of $250 \mathrm{~g}$ for Charentais melon and, by a diameter of $7.5 \mathrm{~cm}$ (23-24 cm of perimeter). In our research, all values surpassed these standards. Circumference ratios were near unity at all stages, indicating round fruit, a characteristic preferred in grading and packing fruit for shipping.

Trichoderma species are well known as biocontrol agents for the control of several crop diseases. Trichoderma spp. can stimulate the growth of plants, including various floricultural and horticultural plants. Trichoderma spp. are opportunistic plant symbionts. They can proliferate, compete and survive in soil and other complex ecosystems.

There are a few reports that investigate $T$. saturnisporum as a biocontrol agent (Diánez et al., 2016) or plant promoter (Diánez et al., 2016; Marín-Guirao et al., 2016). However, this is the first time that it has been described to its field application and its effect on crop yields and fruit quality parameters.

Our results demonstrate that $T$. saturnisporum acts as a biostimulant for nursing and commercial melon crops. Melon productivity increased with $T$. saturnisporum treatments T1 $(13.99 \%)$ and T2 (16.04\%). Our results demonstrate that $T$. saturnisporum (T1 and T2) applied via irrigation on intensive melon crops improved crop yields without negative effects on the fruit quality. This is the first report that describes $T$. saturnisporum as a potential crop yield promoter.

\section{Conclusions}

Our results demonstrate that $T$. saturnisporum act as a biostimulant for nursing and commercial melon crops. Melon productivity increased with $T$. saturnisporum treatments T1 (13.99\%) and T2 (16.04\%). Our results demonstrate that $T$. saturnisporum ( $\mathrm{T} 1$ and T2) applied via irrigation on intensive melon crops improved crop yields without negative effects on the fruit quality. This is the first report that describes $T$. saturnisporum as a potential crop yield promoter.

\section{Literature Cited}

Abul-Baki, A.A. and J.D. Anderson. 1973. Vigour determination in soybean by multiple criteria. Crop Sci. 3:630-637.

Altintas, S. and U. Bal. 2005. Application of Trichoderma harzianum increases yield in cucumber (Cucumis sativus) grown in an unheated glasshouse. J. Appl. Hort. 7:25-28.

Bal, U. and S. Altintas. 2006a. Effects of Trichoderma harzianum on the yield and fruit quality of tomato plants (Lycopersicon esculentum) grown in an unheated greenhouse. Austral. J. Expt. Agr. 46:131-136.

Bal, U. and S. Altintas. 2006b. Application of the antagonistic fungus Trichoderma harzianum (TrichoFlow WP ${ }^{\mathrm{TM}}$ ) to root zone increases yield of bell peppers grown in soil. Biol. Agr. Hort. 24(2): 149-163.

Basoccu, L. and S. Nicola. 1989. Effetti delle condizioni di luce natural, dello stato idrico e del volume del substrato sull'accrescimento in vivaio e sulla producttività del pmodoro in serra fredda. Proceedings 1st National Congress on II Vivaismo articolo, aspetti tecnici, organizzativi e commerciali. Foggia, Italy.

Briggs, G.E., F. Kidd, and C. West. 1920. A quantitative analysis of plant growth. Part I. Ann. Appl. Biol. 7:1003-1023.

Castillo, J.E., F. Herrera, R.J. López-Bellido, F.J. López-Bellido, L. López-Bellido, and E.J. Fernández. 2004. Municipal solid waste (MSW) compost as a tomato transplant medium. Compost Sci. Util. 12:86-92.

Chang, Y.C., R. Baker, O. Klefield, and I. Chet. 1986. Increased growth of plants in the presence of the biological control agent Trichoderma harzianum. Plant Dis. 70:145-148.
Chet, I. 1987. Trichoderma application, mode of action, and potential as biocontrol agent of soilborne pathogenic fungi, p. 137-160. In: I. Chet (ed.). Innovative approaches to plant disease control. Wiley, New York, NY.

Chirino-Valle, I., D. Kandula, C. Littlejohn, R. Hill, M. Walker, M. Shields, N. Cummings, D. Hettiarachchi, and S. Wratten. 2016. Potential of the beneficial fungus Trichoderma to enhance ecosystem-service provision in the biofuel Grass Miscanthus x giganteus in agriculture. Sci. Rep. 6:25109.

Colla, G., Y. Rouphael, E. Di Mattia, C. El-Nakhel, and M. Cardarelli. 2015. Co-inoculation of Glomus intraradices and Trichoderma atroviride acts as abiostimulant to promote growth, yield and nutrient uptake of vegetable crops. J. Sci. Food Agr. 95:1706-1715.

Diánez, F., M. Santos, F. Carretero, and F. Marín. 2016. Trichoderma saturnisporum, a new biological control agent. J. Sci. Food Agr. 96:19341944.

Dickson, A., A.L. Leaf, and J.F. Hosner. 1960. Quality appraisal of white spruce and white pine seedling stock in nurseries. For. Chron. 36:0-13.

Elad, Y., Y. Zvieli, and I. Chet. 1986. Biological control of Macrophomina phaseolina (Tassi) goid by Trichoderma harzianum. Crop Protection 5(4):288-292.

Fernández-Escobar, R., A. Trapero, and J. Domínguez. 2010. Experimentación en agricultura. Junta de Andalucía. Consejería de Agricultura y Pesca, Sevilla, Spain.

Fonseca, J.M. 2005. Yield and postharvest quality of Cantaloupe melons as affected by calcium foliar applications. Vegetable Report, College of Agriculture and Life Sciences, University of Arizona. $<\mathrm{http}: / /$ cals. Arizona.edu $>$.

Harman, G.E., C.R. Howell, A. Viterbo, I. Chet, and M. Lorito. 2004. Trichoderma speciesopportunistic, avirulent plant symbionts. Nat. Rev. Microbiol. 2:43-56.

Herrera, F., J.E. Castillo, A.F. Chica, and L. LópezBellido. 2008. Use of municipal solid waste compost (MSWC) as a growing medium in the nursery production of tomato plants. Bioresour. Technol. 99:287-296.

Herrera, F., J.E. Castillo, R.J. López-Bellido, and L. López-Bellido. 2009. Replacement of a peatlite medium with municipal solid waste compost for growing melon (Cucumis melo L.) transplant seedlings. Compost Sci. Util. 17:31-39.

Jain, A., A. Singh, S. Singh, and H.B. Singh. 2013. Microbial consortium-induced changes in oxidative stress markers in pea plants challenged with Sclerotinia sclerotiorum. J. Plant Growth Regul. 32:388-398.

Lester, G.E. and J.R. Dunlap. 1985. Physiology changes during development and ripening of 'Perlita' muskmelon fruits. Scientia Hort. 26:323-331.

López-Bucio, J., R. Pelagio-Floresa, and A. HerreraEstrella. 2015. Trichoderma as biostimulant: Exploiting the multilevel properties of a plant beneficial fungus. Scientia Hort. 196:109-123.

Luna-Guzmán, I., M. Cantwell, and D.M. Barrett. 1999. Fresh-cut cantaloupe: Effect of $\mathrm{CaCl}_{2}$ dips and heat treatments on firmness and metabolic activity. Postharvest Biol. Technol. 17:201-213

Marín-Guirao, J.I., P. Rodríguez-Romera, B. Lupión-Rodríguez, F. Camacho-Ferre, and J.C. Tello-Marquina. 2016. Effect of Trichoderma on horticultural seedlings growth promotion depending on inoculum and substrate type. J. Appl. Microbiol. 121:1095-1102.

Martínez-Medina, A., J.A. Pascual, E. Lloret, and A. Roldan. 2009. Interactions between arbuscular 
mycorrhizal fungi and Trichoderma harzianum and their effects on Fusarium wilt in melon plants grown in seedling nurseries. J. Sci. Food Agr. 89(11):1843-1850.

Martínez-Medina, A., A. Roldán, and J.A. Pascual. 2011. Interaction between arbuscular mycorrhizal fungi and Trichoderma harzianum under conventional and low input fertilization field condition in melon crops: Growth response and Fusarium wilt biocontrol. Appl. Soil Ecol. 47:98-105.

NFSMI. 2013. Cantaloupe information sheet. National Food Services Management Institute. $<$ http://www.nfsmi.org/Default.aspx>.

Pereira, J.L., R.M.L. Queiroz, S. Charneau, C.R. Felix, C.A. Ricart, F. Lopes da Silva, A. Stecca, C. Steindorff, C.J. Ulhoa, and E.F. Noronha. 2014. Analysis of Phaseolus vulgaris response to its association with Trichoderma harzianum (ALL-42) in the presence or absence of the phytopathogenic fungi Rhizoctonia solani and Fusarium solani. PLoS One 9:e98234.
Pimpini, F. and G. Gianquinto. 1991. Primi resultati sulle modalita di allevamento invivaio di piantina di pomodoro da industria. Riflessi su aecrescimento e produzione in campo. 2 Convego Nazionale "Il vivaismo Octicolo". Foggia, Italy.

Portela, S.I. and M.I. Cantwell. 1998. Quality changes of minimally processed honeydew melons stored in air or controlled atmosphere. Postharvest Biol. Technol. 14:351-357.

Pratt, H.K. 1971. Melons, p. 207-233. In: A.C. Hulme (ed.). The biochemistry of fruits and their products. Academic Press, New York, NY.

Pratt, H.K., J.D. Goeschl, and F.W. Martin. 1977. Fruit growth and development, ripening, and the role of ethylene in the 'Honey Dew' muskmelon. J. Amer. Soc. Hort. Sci. 102:203-210.

Ritchie, G.A. 1984. Assessing seedling quality, p. 65. In: M.L. Duryea and T.D. Landis (eds.) Forestry nursery manual: Production of bareroo seedlings. Martinus Nijhoff/Dr W. Junk, The Hague, The Netherlands.
Rubio, M.B., S. Dominguez, E. Monte, and R. Hermosa. 2012. Comparative study of Trichoderma gene expression in interactions with tomato plants using high-density oligonucleotide microarrays. Microbiology 158:119-128.

Shellie, K.C. and G. Lester. 2004. Netted melons. In: The commercial storage of fruits, vegetables, and florist and nursery stocks. USDA Handbook Number 66. 23 Feb. 2007. <http:// usna.usda.gov/hb66/095nettedmelon.pdf $>$.

Supapvanich, S., K. Boon-Lha, and N. Mhernmee. 2011. Quality attribute changes in intact and fresh-cut honeydew melon (Cucumis melo var. inodorus) cv. 'Honey World' during storage. Kasetsart J. (Nat. Sci.) 45:874-882.

UNECE. 2010. UNECE Standard FFV-23 Concerning Marketing and Commercial Quality Control of Melon edition. United Nations, New York.

Villanueva, M.J., M.D. Tenorio, M.A. Esteban, and M.C. Mendoza. 2004. Composition changes during ripening of 2 cultivars of muskmelon fruits. Food Chem. 87:179-185. 